\title{
APUNTES A INO Y TEMISTO DE FRANCISCO COMELLA
}

\author{
Manuel Caballero GonZÁlez
}

Ludwig-Maximilians-Universität München

\section{Introducción}

En este artículo queremos analizar brevemente la tragedia del dramaturgo español Luciano Francisco Comella' ${ }^{1}$ que lleva por título Ino y Temisto. Nuestra intención es comentar esta obra desde la perspectiva de la tradición mítica de la saga de Atamante para comprender en qué puntos se diferencia la tragedia española de tal relato mítico y qué temas son los ejes principales que Comella ha escogido para su representación trágica.

1 Véase la reciente tesis doctoral de Ma Angulo Egea, Luciano Francisco Comella (1751-1812), otra cara del teatro de la Ilustración (Universidad de Alicante, 2006) sobre este personaje, la controversia que mantuvo con Moratín y un análisis detallado del panorama teatral español de su época. Véanse también F. Nieva, «El teatro de la Ilustración: Moratín y Comella», Debats, 66, 1999, págs. 169-174; Ma Angulo Egea, «Fingir y aparentar. La imagen de las mujeres en el teatro sentimental de Luciano Francisco Comella (1751-1812)», Dieciocho: Hispanic enlightenment, 25-2, 2002, págs. 281-302; Los sainetes misceláneos de Luciano Francisco Comella: «El día de función nueva», «La función casera», «El baile deshecho» y «Juan de la Enreda», en J. Cañas Murillo y J. Roso Díaz (coord.), Aufklärung: estudios sobre la Ilustración española dedicados a Hans-Joachim Lope, 2007, págs. 137-152; F. Doménech (ed.), La comedia lacrimosa española: Gaspar Melchor de Jovellanos «El delincuente honrado»; L. F. Comella «La Cecilia»; L. Fernández de Moratín «El viejo y la niña», Fundamentos, Madrid, 2006. 


\section{Sobre el mito de Atamante}

El relato mítico de Atamante ${ }^{2}$ se puede dividir en tres versiones diferentes según el papel que esta figura desempeñe en ellas. En la versión que denominamos Ino-Frixo-Hele (I-F-H) se presenta al Eólida como homo sacrificans: Ino maquina contra sus hijastros Frixo y Hele y consigue llevarlos al altar del sacrificio por medio de un oráculo de Delfos falso. El carnero de oro los salva de la muerte inminente y los transporta a la Cólquide; en el trayecto Hele se cae del fabuloso animal y da nombre al Helesponto. En la versión que llamamos Ino-Learco-Melicertes (I-L-M) nuestro personaje posee un papel mucho más activo. En ella Atamante, enloquecido (homo furens), mata a su hijo Learco, e Ino, perseguida o también enajenada, salta desde un precipicio con su otro hijo Melicertes. La locura se la ha mandado Hera-Juno por haber criado a Dioniso, un hijo bastardo de su infiel esposo Zeus-Júpiter. Finalmente, en la versión Ino-Temisto (I-T) se narra la muerte de los hijos de Temisto a manos de su madre; Ino, que la servía como doncella, la había engañado para proteger la vida de sus propios hijos. Como Atamante no desempeña ningún papel, lo hemos calificado en esta tercera versión como homo ignauus.

\section{Sobre la tragedia en general}

Lo primero que llama la atención es que la obra se titule precisamente Ino y Temisto, lema que coincide con la tercera de las versiones en las que hemos dividido el mito de Atamante 3 . Decimos que llama la atención porque de esta versión sólo poseemos, en el conjunto de las literaturas griega y latina, tres narraciones más o menos detalladas realizadas por dos autores, a saber Higino (Fab. I. IV) y Nonno (D. IX 302-X 3), y dos alusiones a las desgracias que a la casa de Atamante le produjo el matrimonio con Temisto (Ath. XIII 560 D Kaibel y Anon. Par. 1-8 Westermann). Es decir, que en el considerable volumen de testimonios que poseemos sobre el mito de Atamante 4 abundan las referencias a las versiones Ino-Frixo-Hele e Ino-Learco-Melicertes, pero no a la versión Ino-Temisto.

2 Atamante, hijo de Eolo, gozó de mucha popularidad en la Antigüedad Clásica, como lo demuestran las tragedias que Esquilo, Sófocles y Eurípides dedicaron a su mito. Para la estructuración de esta leyenda nos hemos servido de las reflexiones de T. Gantz, Early Greek Myth. A guide to Literary and Artistic Sources, The Johns Hopkins University Press, Baltimore, I, 1993 (cf. pág. 179).

${ }^{3}$ Comella escribirá cuatro años más tarde, en 1797, otra obra de esta misma saga, Ino y Neifile. Nótese que la denominación «Ino-Temisto» coincide también con la que usa T. Ganz (loc. cit.) para clasificar el mito de Atamante.

${ }^{4}$ Véase A.-C. Soussan, La figure d'Athamas dans la mythologie gréco-latine, Atelier National de Reproduction des Thèses, París, 2010; y la tesis doctoral de M. Caballero González, El personaje mítico Atamante en las literaturas griega y latina (Universidad Complutense de Madrid, 2011), que será publicada próximamente en la colección Classica Monacensia con el título Der Mythos des Athamas in der griechischen und lateinischen Literatur. 
Es posible, sin embargo, que la preferencia por esta versión prácticamente desconocida se halle en la cuarta Fábula de Higino, cuyo título reza INO EVRIPIDIS. No es posible presentar en este momento las enormes disquisiciones que sobre la atribución del contenido de esta Fábula se han realizado en el mundo de la Filología Clásica; tan sólo hemos de señalar que, a pesar de que algunos filólogos de gran renombre como Nauck o Robert negaran que esta Fábula pudiera servir para la reconstrucción de la tragedia euripidea titulada Ino, la amplia mayoría de los estudiosos acepta que Higino presenta en su obra las líneas generales de lo que pudo ser la trama de esta obra que se centra, justamente, en la versión Ino-Temisto, como se ha aludido anteriormente. En realidad, de todas las tragedias escritas por Esquilo, Sófocles y Eurípides y dedicadas al mito de Atamante, sólo la que lleva por título Ino es de aquélla de la que tenemos un testimonio detallado de su trama en un compilador de la Edad Antigua ${ }^{5}$. Este hecho pudo motivar a Comella para que escribiera este drama basado en la mitología griega y latina, género por el que este escritor sentía cierta predilección como lo demuestran sus obras La Andrómaca o Hércules y Deyanira.

En la edición de esta tragedia conservada en la Biblioteca Histórica de la Universidad de Valencia ${ }^{6}$ aparecen al comienzo de la tragedia los personajes que han de actuar en la obra y que en el texto se denominan «personas»? Varios datos merecen ser comentados.

En primer lugar, sorprende que Comella apellide a Ino «Tegea», haciendo referencia a la principal ciudad de la Arcadia, en alusión directa al Peloponeso: en ningún texto de la Antigüedad Clásica se le ha dado a Ino este sobrenombre y tampoco es evidente la razón para hacerlo, ya que la hija de Cadmo se relaciona con Tebas, ciudad en la que tiene lugar la representación, o con Fenicia, de donde era originario su padre, personaje que desempeñará un papel muy destacado en la obra. En segundo lugar, Comella crea una serie de nombres, algunos de ellos basados en famosos personajes históricos o ficticios del mundo heleno, para dar voz a un noble tebano (Adrasto), a un capitán de la guardia real (Creonte), al confidente del rey Atamante (Idreno) o a los hijos de Ino (Safo) y de Temisto (Nimias). Estos dos últimos casos son aún más llamativos, pues todas las fuentes son unánimes en señalar a Ino dos hijos, Learco y Melicertes,

${ }^{5}$ Del Atamante de Esquilo apenas se puede afirmar algo con certeza, ya que sólo disponemos de escasos fragmentos para reconstruir la trama (cf. J. M. Lucas de Dios, Esquilo. Fragmentos y testimonios, Gredos, Biblioteca Clásica, 369, Madrid, 2008; «El Atamante de Esquilo», en J. Costas Rodríguez, coord., Ad amicam amicissime scripta. Homenaje a la profesora Ma José López de Ayala y Genovés, UNED, Madrid, 2005, págs. 89-96). De las dos tragedias de Sófocles tituladas Atamante sólo tenemos brevísimos fragmentos y algunos testimonios indirectos, todos ellos muy tardíos, sobre la trama de uno de ellos (escolios a Ar. Nu. 257); del Frixo de Sófocles no se sabe casi nada y tan sólo poseemos conjeturas realizadas por estudiosos modernos. De los dos Frixo de Eurípides se han encontrado los argumentos sobre estas obras en dos papiros de Oxirrinco (P. Oxy. 3652; 2455, para el primer Frixo y el P. Oxy. 2455 para el segundo Frixo), que, obviamente, Francisco Comella no pudo conocer.

6 Véase http://trobes.uv.es/tmp/_webpac2_1649202.15231.

${ }^{7}$ Esta denominación procede de la expresión latina iunctura dramatis personae. 
y no uno solo llamado Safo ${ }^{8}$. Por otro lado, los textos que hablan de los hijos de Temisto suelen hacer referencia a un número superior a $\operatorname{dos}^{9} \mathrm{y}$, si bien hay disparidad entre unos nombres y otros, en ninguna fuente se halla el nombre de Nimias. En tercer lugar, extraña que el dramaturgo catalán hable de los «sequaces de Cadmo», ya que ni éstos ni tampoco el padre de Ino tienen nada que ver con esta versión del mito de Atamante.

Respecto a la localización de la obra teatral, Comella se inclina por el ámbito geográfico que predomina en la versión I-L-M del mito de Atamante, esto es, la ciudad de Tebas, y obvia la ubicación habitual de la versión I-F-H, es decir, Orcómeno. Esta opción intenta ser coherente con el emplazamiento de la acción dramática en Hyg. Fab. I, ubicada en un palacio real (regia), y con la importancia que debía de tener Tebas en la Antigüedad al ser la capital de Beocia ${ }^{10}$.

\section{Análisis de la obra}

Analicemos en este momento los rasgos principales de los cinco actos haciendo hincapié en aquellos aspectos que son más relevantes para nuestra argumentación.

\section{Primer acto}

En la primera escena, el espectador se encuentra con una Ino disfrazada como esclava en el palacio de Atamante; es evidente el empeño de la hija de Cadmo por pasar desapercibida. El cariño que muestra a Safo, sin embargo, la descubre ante el fiel siervo Adastro. La mención a la fidelidad del criado tebano puede aludir al frg. 822a Kannicht ${ }^{11}$, en donde se hace referencia a un

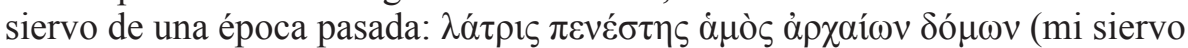
cautivo de la antigua casa) ${ }^{12}$.

${ }^{8}$ Tan sólo en Zen. Vulg. IV 38 y en el Schol. in Lyc. Alex. 107 Scheer se puede leer el nombre de un tercer hijo, más exactamente de una hija llamada Euriclea.

${ }^{9}$ Solamente en Hyg. Fab. I se habla de dos hijos porque el compilador intenta explicar de un modo lógico cómo pudo confundir Temisto a sus hijos con los dos vástagos de Ino.

${ }^{10}$ A favor de esta interpretación están los diferentes topónimos beocios que aluden a los hijos de Atamante y Temisto (el monte Ptoo, las ciudades de Eritras y de Esqueno y el río Esqueneo), así como la trama en general de las Dionisíacas de Nonno, en cuyo libro v se describe la fundación de Tebas por parte de Cadmo, ciudad en la que se supone que tienen lugar los acontecimientos que se narran al final del libro IX y al principio del X. En contra de este emplazamiento se hallan los testimonios de Hyg. Fab. IV, cuyo inicio afirma claramente: Athamas in Thessalia rex, y de Apollod. I 9, 2 (texto que coincide con el Schol. in Lyc. Alex. 22 Scheer) que da fe de un desplazamiento de Atamante desde Beocia hacia Tesalia.

${ }^{11}$ R. Kannicht, Tragicorum Graecorum fragmenta (TrGF). Eurípides, Vandenhoeck \& Ruprecht, Göttingen, 2004.

${ }^{12}$ En cambio, el frg. 822b Kannicht parece sugerir un enfrentamiento entre Ino y un criado a causa de la simiente tostada, elemento que pertenece a la versión I-F-H. 
La madre de Safo lleva puesto un velo que, según Comella, se desliza un poco hacia atrás cuando Ino muestra todo su afecto por Safo; de este modo, Adrasto no alberga ya duda alguna sobre la identidad de la esclava que tiene delante de sí. Nosotros creemos que la alusión al velo - del que Ino hará mención de una manera explícita al comienzo del tercer folio del manuscrito conservado en la Biblioteca Histórica de la Universidad de Valencia- es un guiño al lector culto para remitirle al poema de la Odisea. En efecto, en $O d$. v 333-353 se puede leer cómo Ino-Leucótea se aparece al náufrago Odiseo y le ayuda en su gran tribulación. En el v. 346-347 la diosa marina le ofrece un velo para que se lo ate por debajo del pecho y así llegue sano y salvo a la tierra de los feacios:

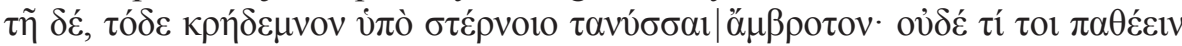

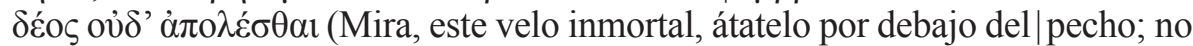
temas ni sufrir nada ni perecer). Al llegar a tierra firme, Odiseo debe lanzar de nuevo al mar el velo, que la propia Ino recogerá unos versos más adelante (Od. v 461-462).

En la primera frase que Adrasto dirige a su antigua señora, se dice: «Dame tus reales pies infeliz Ino». El término «infeliz» nos recuerda inmediatamente los proverbiales dolores de Ino ('Ivoũ $\left.\alpha_{\alpha} \chi \eta\right)$, tal y como refieren Zenobio (Vulg. IV 38), Aristides (Or. XLVI) o la propia Suda (1 381). Es más, al comienzo del segundo folio, Adrasto utiliza este adjetivo para describir la ropa de esclava que Ino lleva en ese momento; es muy probable que Comella quiera aludir veladamente a la famosa expresión de Ar. Achar. 433-434 en donde se hace referencia a los harapos de Ino (jók $\alpha$ ), concepto que se suele atribuir, por cierto, a la obra de Eurípides titulada Ino, tragedia en la que parece que Comella quiere basar su historia.

Este calificativo para la hija de Cadmo contrasta con el que la propia Ino usa para describir a su marido Atamante cuando éste prefirió el cariño de Temisto ${ }^{13}$ al amor de su primera cónyuge: «que por Temisto, el pérfido Atamante|me separó del trono». El adjetivo «pérfido» alude a otras formas semejantes de caracterizar a Atamante en la poesía latina clásica y post-clásica omitiendo siempre la mención de la locura. En Ou. Fast. VI 555 se halla el adjetivo improbus, término mucho más apropiado que el de «pérfido» para el contexto que Ovidio sugiere, que, de hecho, es bastante parecido al que en esta tragedia se presenta: en los Fastos, Atamante engaña a Ino con una esclava. La diferencia con el caso presente es que la esclava nunca tuvo rango real y Atamante cometía su adulterio a escondidas y no públicamente. En época post-clásica, Estacio evita el término furibundus para Atamante e insiste en su maldad en el poema de las Silvas (Silu. II 1, 143) o en la compasión al aplicar la voz infelix a Atamante (Theb. I 13; III 186).

En el segundo folio, Ino da una razón de su expulsión que no aparece nunca en la literatura griega o latina: Atamante la repudia porque ella ha cometido

\footnotetext{
${ }^{13}$ Comella ofrece por vez primera en la literatura una fecha para los fatales acontecimientos de la versión I-T: aproximadamente tres años después de que Atamante abandonara a Ino.
} 
adulterio. Lo habitual es que sea Atamante el que tenga una relación escondida ${ }^{14}$ y no Ino, si bien en el Anon. in Rh. 145, 10-146, 6 Rabe se afirma que la hija de Cadmo tuvo relaciones sexuales con Zeus en un claro intento de asimilar la figura de Ino a la de su hermana Sémele. El adulterio en el universo femenino del mito de Atamante no aparece nunca narrado y sólo cabe suponerse en el mencionado pasaje a la Retórica de Aristóteles y en Hyg. Fab. CLVII, en donde se dice que Leucónoe fue hija de Temisto y Neptuno.

La localización de Cadmo en Tesalia y la fuga de Ino a dichas tierras no tienen tampoco precedente alguno que nosotros sepamos. En Hyg. Fab. IV Atamante encuentra a Ino en el Parnaso, es decir, en la región de la Fócida y no en Tesalia, con la que Ino no tiene vinculación alguna. De una guerra entre Cadmo y Atamante no hay noticia alguna. Es más, el dramaturgo español modifica completamente la trama de la Fabula latina y propone un acercamiento voluntario de Ino a Tebas ${ }^{15}$, incitado por un capitán de la guardia real llamado Creonte. En el texto latino es Atamante el que misit qui eam adducerent (y envió \{a unos servidores\} para que se la llevasen \{ante él\}) con una motivación evidentemente amoroso-erótica. En la tragedia española a Ino sólo la mueve el afecto materno. Comella salva el escollo de cómo Ino podía llegar a ser esclava de Atamante por medio de un personaje tan influyente en los asuntos de palacio como el capitán de la guardia. De este modo, el autor español evita presentar a Atamante como adúltero de Temisto, cuyas sospechas y dudas acerca de su marido, por cuestiones sexuales, tampoco tienen cabida en esta tragedia.

Comella presenta a Ino como una nueva sabina que halla su corazón dividido entre el amor de su padre y el de su marido, puesto que lo sigue llamando «esposo» a pesar de que Atamante la haya repudiado y la haya expulsado de su patria. Es decir, que Comella se decanta por la imagen positiva y virtuosa de Ino y no por aquella que despunta en los albores de la literatura griega como asesina de sus hijos ${ }^{16}$.

En la segunda escena, entra Temisto con su séquito de guardias y de esclavas y proclama alegremente el victorioso retorno de su marido a Tebas. Temisto califica las quejas de Ino como injustas ${ }^{17}$ y tacha a la hija de Cadmo de orgullosa y arrogante, tal y como Adrasto había hecho con la propia Temisto poco antes. Ésta se jacta de los males de la familia de Ino (Cadmo viene encadenado a Tebas) y le desea a ésta un cúmulo infinito de desgracias. De esta manera, Comella da

${ }_{14}$ Así se ve, por ejemplo, en Ou. Fast. VI 553-558; Filostéfano ( $F H G$ 37), en cambio, indica que Atamante engaña a Néfele con la propia Ino.

${ }^{15}$ Comella yerra y sitúa el río Ismeno, famoso por la batalla contra Hipomedonte (Stat. Theb. IX), en Tesalia, cuando, en realidad, «ce fleuve coule le long du flanc est de la Cadmée mais en dehors du rempart de Thèbes» (R. Lesueur, Statius, Publius Papinius. Thébaïde, Belles Lettres, Série latine, 318, París, 2003, pág. 146, nota 21), es decir, en plena Beocia.

${ }_{16}$ Véase, por ejemplo, el famoso pasaje de E. Med. 1282-1289.

17 Valerio Flaco ( 279 ) también utilizaba el adjetivo iniustas en relación a Ino (y a Atamante), pero no lo refería a sus quejas, sino a los altares de los sacrificios, en clara alusión a la maquinación que la hija de Cadmo había preparado contra Frixo y Hele y al sacrificio que el propio Atamante iba a realizar con la vida de sus hijos. 
cuerpo en la obra al contenido de los mencionados 'Ivoṽ $\varsigma$ ä $\chi \eta$, si bien cambia el argumento que Zenobio nos transmite e incorpora a las desgracias de Ino la derrota bélica de su padre.

En el cuarto folio, Adrasto se hace eco del frg. 407 Kannicht en el que ex-

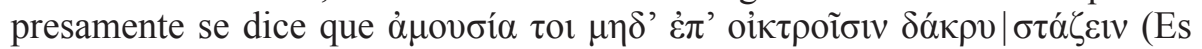
maleducado no derramar lágrima alguna por los desgraciados) o del frg. 415 Kannicht en que el interlocutor se dirige directamente a la reina: ö $\alpha \alpha \sigma \sigma \alpha$,

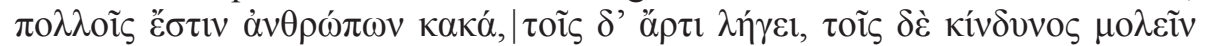
(¡Reina!, muchos hombres tienen desgracias, |en unos, acaban de cesar, en otros, el peligro ha de llegar). El frg. 416 Kannicht también habla de la osadía que intenta ocultar las desgracias y cubrir los infortunios; los tres fragmentos se atribuyen a la Ino de Eurípides. Respecto al juicio de las obras ocultas, en clara referencia a Ino escondida en las ropas de una esclava, se podría traer a colación el frg. 835 Kannicht, que habla de los males que los mortales pueden ocultar a los dioses, si bien este fragmento se suele asignar a uno de los Frixo euripideos.

En la tercera escena, Comella se aleja de la famosa historia de Atamante que lo hace uno de los prototipos de locura y propone como personaje «ciego de furia» al padre de Ino, Cadmo. Y es el propio Atamante el que así habla. La descripción del furor bellicus de Cadmo alude claramente a los poemas de la Ilíada y de la Farsalia; sin embargo, es fácil imaginarse de la misma manera, tal y como narra Nonno de Panópolis al inicio del décimo canto de sus Dionisíacas, el furor de Atamante al matar a su hijo Learco en una cacería. Es más, el propio dramaturgo vincula ese furor, cercano al «enojo fiero», con la equivocación o el yerro, producto de quien ha perdido el seso o la razón. Respecto a la diferencia ciceroniana ${ }^{18}$ entre insania y furor, Comella no duda en poner ambos conceptos uno al lado del otro al referirse a Cadmo, ya que habla de «su insano furor».

La quinta escena nos presenta un rasgo importante para este análisis. Atamante abre su corazón a Idreno y le revela cómo teme que, en más de una ocasión, la locura se esté apoderando de su mente y de su cuerpo. Nosotros creemos que la referencia a los «silvidos», al «espumoso humor» y a la «serpiente» que se lee en el siguiente folio es una clara alusión al poema de Nonno de Panópolis.

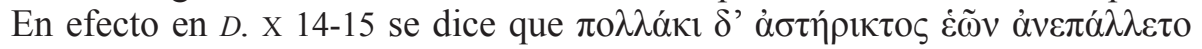

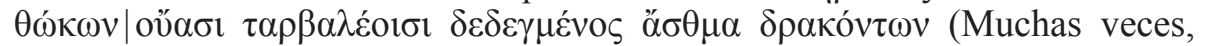
inquieto, saltaba de su asiento, |y recibía el silbido de las serpientes en sus terribles oídos) y un poco más abajo (D. X 18-20) el poeta del s. V d. C. indica que

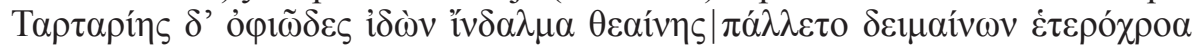

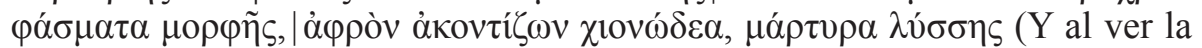
apariencia cubierta de serpientes de la diosa Tartaria,|se estremeció temiendo la variada figura de su forma, que lanzaba una espuma parecida a la nieve, signo de locura).

\footnotetext{
${ }^{18}$ Cf. Tusc. III 8-11.
} 
De una manera muy inteligente, Comella presenta la locura de Atamante como un proceso de interiorización y una descripción metafórica de lo que en la Antigüedad se había descrito con la ayuda de las Euménides y de las Erinias. Es más, la respuesta de Idreno se remite al mismo proceso interior, vinculándolo estrechamente al delito y al crimen, como Cicerón narraba en el famoso paso de Pis. XLVI-XLVII:

Nolite enim ita putare, patres conscripti, ut in scaena videtis, homines consceleratos impulsu deorum terreri furialibus taedis ardentibus; sua quemque fraus, suum facinus, suum scelus, sua audacia de sanitate ac mente deturbat.

No queráis imaginaros, padres conscriptos, como veis en el escenario, a hombres manchados de sangre que son aterrorizados por las Furias con teas ardientes, impelidas por los dioses; su propio engaño, su crimen, su delito, su imprudencia les hacen perder el sentido y la razón.

Es más, en el último verso del primer acto Atamante refiere sus propias «demencias», pero, a diferencia de lo que las literaturas griega y latina nos presentan, Atamante entiende que sólo pudo abandonar a la casta y virtuosa Ino en una acto de enajenación mental. Esta locura de Atamante es totalmente nueva.

\section{Segundo acto}

En la primera escena, se narra cómo Cadmo desprecia la libertad otorgada por Atamante; es evidente que toda la acción que sigue a este anuncio no tiene precedente alguno en la literatura griega o latina.

En la tercera escena, Cadmo acusa directamente a Atamante de haber urdido la trama que ha injuriado tan gravemente el honor de Ino. Si bien el contenido de la trama (la acusación de que Ino es una adúltera) es nuevo, no lo es, en cambio, esta actitud conspiradora de Atamante. En los primeros estadios de la versión I-F-H, Atamante maquina contra Frixo con la complicidad de su esposa Ino. Así

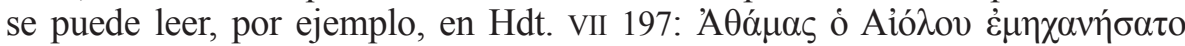

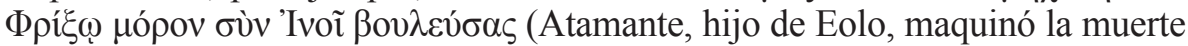
de Frixo, tras haberlo así determinado con Ino). Comella nos presenta, pues, un rasgo muy antiguo del Atamante sacrificans, el maquinador, y lo aplica a la versión I-T, en donde Atamante nunca poseía este rasgo ${ }^{19}$.

Llama la atención que Cadmo refiera que Temisto provenga de Corinto: ninguna fuente literaria atestigua este hecho. Comella ha podido ubicar en esta ciudad el origen de Temisto con la intención de llamarla, educadamente, prostituta: recuérdese que la expresión 'muchacha de Corinto' significaba en la Antigüedad 'meretriz', lo mismo que la locución 'vivir como un corinto'

\footnotetext{
${ }^{19}$ Tampoco aparece un Atamante maquinador en la versión I-L-M.
} 
hacía referencia a la vida lujuriosa, desenfrenada, disoluta e inmoral de sus habitantes ${ }^{20}$.

En la cuarta escena, Adrasto, fiel servidor de Ino, comienza el cuadro con una metáfora muy interesante: «De la lóbrega nuve del disgusto». Comella se sirve de esta figura poética para aludir a Néfele, que en griego significa precisamente nube. «Lóbrega» es un calificativo muy acertado pues, como se sabe, la relación entre Néfele e Ino ha sido siempre muy tormentosa.

En la quinta escena, Temisto, ultrajada al ver cómo Atamante abraza al hijo de su rival, Safo, y al padre de quien la antecedió en el trono, Cadmo, se encoleriza contra Ino, a la que no duda en llamar «fiera». Esta imagen negativa de Ino sólo se plasma en la tradición mítica de Atamante en la versión I-F-H; en la versión I-L-M, Ino sólo vendrá caracterizada como una bárbara cruel en la época clásica griega (Eurípides la hace asesina de sus dos hijos en Med. 1282-1289) y en algunos escritores de la época helenística. Poco a poco, esta imagen negativa de Ino se irá purificando con los siglos hasta llegar a la flebilis Ino de Horacio (Ars. 123), es decir, a una mujer que sufre temblorosa la desgracia y el dolor ${ }^{21}$.

Al final de la escena, Temisto, dolida, lanza amenazas contra todo aquel que ose urdir contra su persona «tramas siniestras» y asegura: «el rayo de mi furia antes que el trueno propagará el estrago en sus cabezas». En realidad, esta furia enloquecida de Temisto no se halla en las Fábulas de Higino; sólo Nonno de Panópolis alude a la locura de Temisto en relación con el fallido intento de matar a los hijos de su rival Ino. En efecto, en $D$. x 1-2 se dice que " $\Omega \varsigma \dot{\eta} \mu \grave{\varepsilon} v$

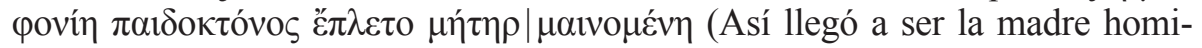
cida, asesina de sus hijos, | cuando se volvió loca), lo cual está en perfecta sintonía con la expresión que Comella utiliza para dar por acabada esta secuencia.

En la séptima escena, Atamante ve a Ino como esclava y le pregunta a Adrasto por su procedencia. Éste contesta que es de Tesalia'22, según la lógica de toda la obra. Aquí no se produce la famosa òvayvópıøıৎ entre Atamante e Ino, sino que habrá que esperar a unos versos posteriores. En cualquier caso, el planteamiento de Comella se opone claramente a la disposición de la cuarta Fábula de Higino, en donde se indica claramente que fue el propio Atamante quien hizo venir a Ino desde el Parnaso hasta su palacio y que fue él quien la ocultó como esclava para que Temisto no la reconociera. En la tragedia española, Temisto toma la iniciativa de emplear a Ino como sierva de alcoba, sin saber la verdadera identidad de su esclava.

${ }^{20}$ En el Acrocorinto se hallaba el templo de Afrodita. Las hieródulas que lo servían practicaban la prostitución sagrada, es decir, que dichas sacerdotisas creían que haciendo el acto sexual veneraban y honraban a la diosa. Cada atardecer salían en busca de nuevos adoradores de Afrodita.

${ }^{21}$ Cf. M. Caballero González, «¿Es de veras Ino tan flebilis», Florentia Iliberritana, 25, 2014, págs. 9-29.

22 Téngase en cuenta que en el frg. 422 Kannicht, que se atribuye a la Ino de Eurípides, se hace referencia a los tesalios, si bien el contenido del fragmento difiere de la intención última de Comella: en el texto griego se apela a un proverbio antiguo en el que se afirma que quien procede de dicha tierra no es digno de crédito o de confianza. 


\section{Tercer acto}

En la primera escena, el padre de Ino insiste en los peligros que acechan la vida de Safo, ya que se halla sometido al «odio y furor de una madrastra». Por vez primera en toda la obra aparece explícitamente un tema fundamental en la tradición mítica de Atamante: el de la madrastra. Este motivo es un eje principal en la versión I-F-H y, es lógico que así sea también, en la versión I-T. En realidad, Comella asocia magistralmente las dos causas principales que provocan todos los tristes acontecimientos del relato mítico de Atamante: el odium nouercae para la versión I-F-H - insistimos, se supone que también para la versión I-T- y el del furor para la versión I-L-M. El dramaturgo español ha comprendido muy bien el mito de Atamante.

En la segunda escena, el capitán de la guardia, Creonte, habla con Adrasto y le pregunta por la suerte del «infeliz Rey». Como se ve, Comella alterna en la obra este adjetivo tanto para Ino como para Atamante, principalmente, y se suma, de este modo, a la visión benévola que la poesía latina de la Época de Plata presentaba de Atamante, sobre todo Estacio, como ya hemos visto. Por otro lado, el infeliz destino de Atamante se contrapone con el abrazo que Cadmo dará a su hija Ino «en suerte más felíz».

En la cuarta escena, Temisto cree que Nimias será el príncipe heredero y aleja el temor que la zozobraba, es decir, que su hijo fuese «súbdito infeliz del hijo de Ino». Una vez más sale el tema de la infelicidad, un tema capital en esta tragedia. De este modo, la escena termina con la insistencia de Ino en no quitarse el velo de la esclavitud, a pesar de que Temisto la haya manumitido: «asi lo exîge|la baxeza infeliz de mi destino».

En la quinta escena, en el decimosexto folio concretamente, Temisto oye de los labios de Atamante el error que ha cometido: el verdadero sucesor al trono de Tebas no es su hijo, sino el de Ino. Lo que, sin embargo, le resulta a Temisto imperdonable es que Atamante le haya ocultado el nombramiento del futuro heredero al trono mientras toda Tebas tenía conocimiento de ello. Temisto refiere cómo ha nacido vasalla en Corinto, pero que su espíritu excede la nobleza de reyes y nobles. Esta idea posee ciertas reminiscencias del frg. 831 Kannicht, que habla de la libertad de espíritu que tienen muchos esclavos en relación con la mezquindad de sus dueños; sin embargo, este fragmento se suele asignar a uno de los dos Frixo de Eurípides y no a su Ino.

El tema de la felicidad sigue muy presente en todo este acto, como se comprueba en la parte final de la séptima escena, en donde Atamante refiere que su «infeliz» esposa no tiene la culpa de los errores que él ha cometido, o al principio de la siguiente, cuando Cadmo parte hacia Tesalia llorando el destino «de su infeliz hija».

\section{Cuarto acto}

En la segunda escena, Comella describe a Temisto como una nueva Medea, que no duda en quejarse de que su marido sea un «bárbaro traidor, que infiel 
quebranta|las leyes del amor». En efecto, el motivo se asemeja al de Medea: un marido que abandona a su actual mujer por otra; la esposa despechada sufre enormemente y lo paga con su(s) hijo(s), a quien(es) mata. Es cierto que también hay notables diferencias entre ambas mujeres: Medea es la primera esposa de Jasón; Temisto, es la segunda. Medea es una bárbara de la Cólquide; Temisto es una griega, en este caso de Corinto. Medea mata a sus dos hijos voluntariamente; Temisto arrebata la vida de su único hijo accidentalmente. Es más, Medea huirá triunfante hacia Atenas en la homónima obra de Eurípides, Temisto, en cambio, se quitará la vida al comprobar el fatal error cometido. Sin embargo, y a pesar de las divergencias señaladas, parece que Comella tiende a identificar la figura de Temisto con la de Medea, así como Eurípides ejemplificó a la bárbara maga de la Cólquide con la filicida hija de Cadmo.

En la siguiente escena, Atamante habla de nuevo de «insano furor». Si en la tercera escena del primer acto se atribuía a Cadmo una furia desmesurada en el campo de batalla, en este momento se le aplica a Temisto, destrozada por el despecho de Atamante. Tres escenas posteriores, en la sexta, Ino habla de nuevo del «furor» de Temisto y teme que la altiva reina atente contra la vida de Safo. Por eso, ella misma ha de vigilar por la vida de su vástago.

En la séptima escena, Creonte anuncia a Cadmo que su nieto ya es heredero de la corona y «del Reyno la esperanza». Esta idea recuerda el concepto que se

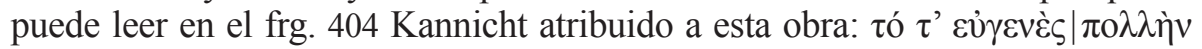

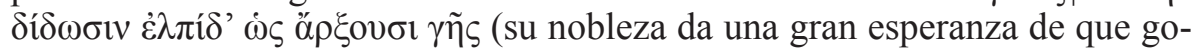
bernarán el país).

En la novena escena, Ino le explica a su padre por qué abandonó la tierra patria: su hijo Safo estaba «en poder de una madrastra». Este tema justifica la llegada de Ino al palacio de Atamante y su humillante condición de sierva: con el fin de poder abrazar al hijo de sus entrañas, Ino ha sido capaz de abandonar su posición de noble y de rebajarse al estado de servidumbre. Este amor filial

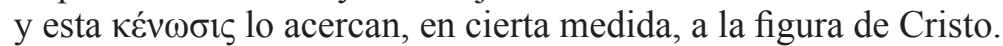

En la duodécima escena, Temisto se presenta y pregunta intencionadamente a Ino si ella está dispuesta a llevar a cabo todo lo que esté en su mano «para hacerla felíz». Ino le responde que en todo la servirá «esta infeliz mísera esclava». El juego conceptual que Comella nos propone es extraordinario: en realidad, la que es infeliz no lo será y la que procurará por todos los medios la felicidad termina sus días desdichada y desgraciada.

En el vigesimocuarto folio, Temisto descubre a Ino su plan, una vez que le ha advertido de que en el palacio se rumorea que Ino anda en él escondida con algún disfraz o disimulo. Según, la cuarta fábula de Higino ${ }^{23}$, Temisto es engañada del siguiente modo:

Rei consciam quam captiuam esse credebat ipsam Inonem sumpsit, et ei dixit ut filios suos candidis uestimentis operiret, Inonis filios nigris.

${ }^{23}$ En la primera, es una anónima nodriza la que lleva a cabo la estratagema que salva a los hijos de Ino. 
Ino suos candidis, Themistonis pullis operuit; tunc Themisto decepta suos filios occidit

Le dio a conocer el hecho a la misma Ino, a la que creía su esclava, y le dijo que vistiera a sus hijos con ropas blancas y a los hijos de Ino, con negras. Ino vistió a los suyos con blancas y a los de Temiso, con negras. Entonces, Temisto, engañada, mató a sus hijos.

Comella, en cambio, omite la artimaña de Ino y propone un método más directo y menos sutil: Temisto encarga a Ino que sea ella misma la que apuñale a Safo mientras éste duerme. Ino confiesa a Temisto que su cobardía no le permite llevar a término la obra encomendada; Temisto la denuesta, pero le encarga que le dé aviso cuando todos duerman porque será ella la que se encargue de matar al hijo de Ino. El dramaturgo español muestra, por lo tanto, una Temisto cruel, vengativa y decidida a la acción, imagen que concuerda con la que la tradición nos ofrece de ella.

En la decimotercera escena, en un soliloquio lleno de patetismo, Temisto confiesa «el furor que le anima»: está resuelta a matar al «vástago infeliz que usurpa el trono|á un hijo mío». Si en Ovidio (Met. IV 484-485) son el Llanto, el Pavor, el Terror y la Insania quienes acompañan a Tisífone camino de la casa de Atamante, aquí es la venganza, la envidia y el odio, la rabia y el enojo los que van de la mano del furor de Temisto.

Comella pinta a Temisto, en definitiva, como un Athamas furens. Se remite a la tradición clásica para describir cómo las furias se le acercan con puñales $\mathrm{y}$ venenos (indicio que recuerda el ataque de Tisífone en las Metamorfosis de Ovidio). Es más, Comella describe fisícamente la locura de Atamante como lo hacía, por ejemplo, Calístrato (Imag. XIV) al detallar un cuadro pintado en las escarpadas orillas de la Escitia. Comella remite la espuma a la imagen de las furias; a Temisto le corresponden los brazos exaltados, el pecho enfurecido, los cabellos erizados y los ojos encendidos. Pero Temisto se distancia de la furia de Atamante:

[...] mas no soy una furia, no, soy mas que una furia; Soy una madre ciega, y despechada;

Una esposa zelosa de amor ebria.

Comella logra un efecto sorprendente en su representación teatral.

\section{Quinto acto}

Este acto comienza con un soliloquio de Ino en lo profundo de la noche y de la oscuridad. Todos duermen - al menos, eso parece-, menos Ino y sus penas. Este principio recuerda el frg. 398 Kannicht, el primero de los atribuidos a la tra-

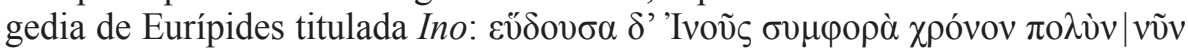

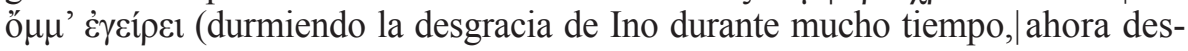
pierta los ojos). 
El tema principal del soliloquio es el de la maternidad, argumento que atraviesa de una manera general toda la obra; de hecho, el tema de la madrastra, que es un eje fundamental en el mito de Atamante, sobre todo en las versiones I-F-H e I-T como hemos señalado anteriormente, está íntimamente vinculado al de la maternidad, puesto que, en principio, la madrastra odia a sus hijastros porque éstos ponen en peligro el honor o el bienestar de sus propios hijos. Aquí, sin embargo, sólo se presenta el odium nouercae en una sola dirección, esto es, el odio de Temisto hacia Safo, hijo de Ino. Bien se podría haber presentado la dirección opuesta de este argumento, es decir, el odio de Ino hacia Nimias, hijo de Temisto, y, supuestamente, principal candidato al trono de Tebas. Sin embargo, Comella ha optado, como lo hace la tradición mítica de Atamante para esta versión, por la imagen positiva de Ino, dechado de virtudes, que jamás concibe maquinar contra el hijo de Temisto para que su propio vástago se convierta en príncipe tebano.

Insistimos, lejos queda la Ino maquinadora de la versión I-F-H tal y como nos la presenta la tradición mítica en la literatura griega y latina de todos los siglos, o la Ino asesina de Eurípides que se atreve a cometer un doble filicidio y a tirarse a continuación por un precipicio. Es cierto que Ino actúa en la versión I-T de un modo tal que conducirá a la muerte al hijo o a los hijos de Temisto, pero su acción viene motivada, explicada y justificada por el amor materno que se afana en salvar la vida de su vástago y no por un odio asesino dirigido contra la descendencia de Temisto.

La segunda escena, que es, prácticamente también un soliloquio, esta vez de Temisto, nos presenta la ira y la furia vengativa de Temisto. Ya hemos visto cómo el cuarto acto acababa con una descripción vívida y detallada de la furia que enajena a la madre de Nimias. Sin embargo, esta furia no puede ser comparada con la $\mu \alpha v i ́ a$ o con el furor enviado a Atamante en la versión I-L-M tal y como se narra en las literaturas griega o latina. La locura de Temisto no es un castigo de los dioses (E. Med. 1284) o de la celosa Hera a causa de la crianza de Dioniso; la alienación mental de Temisto responde a la furia vengativa de quien, lejos de perder el sentido, está perfectamente cuerdo y actúa conscientemente contra su prójimo. No es la razón lo que ha perdido Temisto, sino la confianza en su marido Atamante y la esperanza de que su hijo sea un día monarca de Tebas.

Esta actitud de Temisto sólo encuentra un parecido en dos pasajes del mito de Atamante: en Filostéfano y en Pausanias. En efecto, en FHG 37, Filostéfano vincula del siguiente modo las versiones I-F-H e I-L-M:

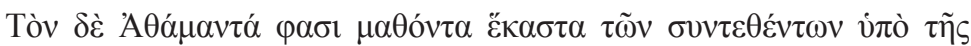

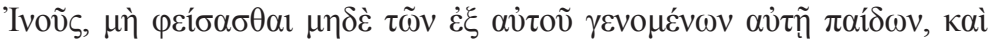

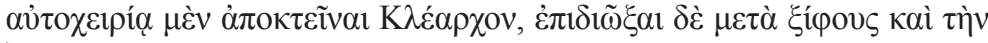
'Ivஸ́.

Dicen que Atamante, al tener conocimiento de cada cosa de lo planeado por Ino, no tuvo misericordia de ninguno de los hijos que ella había 
tenido de él, sino que con su propia mano mató a Clearco; después, persiguió con la espada también a Ino.

Más claro si cabe es el texto de Pausanias. En Paus. I 44, 7 se lee lo siguiente:

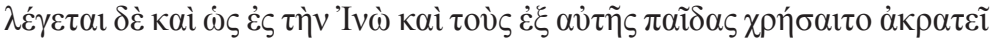

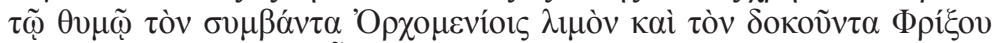

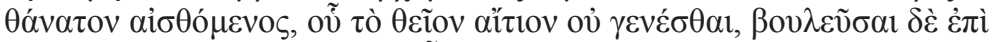

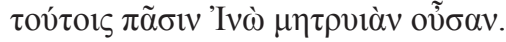

Por otro lado, se cuenta que contra Ino y sus hijos empleó un ardor desmesurado, ya que comprendió que el hambre que acaeció a los de Orcómeno y la supuesta muerte de Frixo no eran por causa divina, sino porque Ino lo había determinado todo ello, como madrastra que era.

Es decir, que Atamante no se vuelve loco por una furia divina que le roba las mientes, sino que carga contra Ino y sus hijos 'enloquecido' por una ira vengativa al verse profundamente insultado, engañado y ultrajado. Temisto actúa por esta misma razón.

Ino cae desmayada al ver como Temisto entra en el cuarto de su hijo para matarlo. En nada se parece este personaje al de la versión I-F-H o a la malvada figura de la versión I-L-M.

En la sexta escena, Atamante se asusta ante las manos de Temisto manchadas de sangre y le pregunta qué ha hecho, llamándola «malvada Corintia». Temisto, sin muestra alguna de arrepentimiento, se jacta orgullosamente de haber vengado el ultraje del padre «en la sangre inocente de tu hijo». Es la misma actitud que tuvo Medea al matar a sus hijos. Lo que cambia es el motivo: Temisto ha actuado para que Nimias fuese rey. Atamante exige ver el cuerpo de Safo y tiembla de ira, pero Temisto se obstina en la justicia que avala su crimen. Ambos se insultan llamándose fieros.

En la última escena, aparece Cadmo y explica todo lo que ha pasado: él y Creonte se llevaron a Safo a las naves con el fin de escapar por la noche y dirigirse a Tesalia. Sin embargo, el Capitán de la Guardia, previsor, temió que Atamante quisiera ir a ver al muchacho dormido y puso en su lugar al hijo de Temisto, Nimias. Comella, pues, se distancia del motivo ofrecido en las Fábulas de Higino, que proponían el trueque del pijama como causa de confusión y de desatino para Temisto. El dramaturgo español va mucho más allá y cambia, no la ropa, sino a los propios niños. Y no es Ino o una nodriza la que lleva a cabo el cambio del aposento, sino el padre de Ino, Cadmo, y el capitán de la guardia real, Creonte.

Atamante se llama «infeliz padre», puesto que, en el intento de recuperar a un hijo, ha perdido a otro en el camino. Cadmo aclara que Temisto se había servido de Ino, «de tu infeliz esposa», para intentar matar a Safo. Entonces Atamante cambia su actitud hacia Ino y la llama «dulce esposa» y destina a Temisto, parricida, al destierro: debe volver a Corinto. El Eólida explica que el 
delito de ser verdugo de la propia sangre halla su causa en la feroz soberbia y en la ciega envidia de Temisto. A él, en cambio, el furor lo cegó hasta llegar a repudiar a su mujer calumniándola. Como se ve, aquí la locura funciona en el caso presente como una especie de 'pasión' que enajena el espíritu y deslumbra la razón hasta obligarla a cometer atropellos y delitos enormes.

Atamante revela a Temisto la verdadera identidad de la esclava Tegea y la hija de Hipseo, en un último arrebato de ira y de soberbia, se quita la vida delante de todos, mientras con ello expresa su deseo de limpiar la sangre derramada de su hijo y de maldecir la existencia de Atamante recién inaugurada.

La obra termina con un Atamante que se retira, amoroso, con Ino y con su hijo Safo. Los últimos versos, pronunciados por Adrasto, ofrecen al espectador una moraleja ética: hay que respetar los designios del Cielo y marchar por el recto camino de la virtud si se quiere escapar al riguroso castigo divino.

\section{Comentarios Generales}

Comella realiza una adaptación del mito de Atamante a la escena española del s. XVIII según la versión I-T. Como ya hemos señalado en los comentarios particulares a cada uno de los actos que componen esta tragedia, el dramaturgo catalán se distancia en no pocos momentos y en no pocos conceptos de la tradición mítica de esta versión tal y como ha llegado hasta nosotros en la principal fuente que nos transmite esta historia: las Fábulas de Higino. Conviene que en este momento nos detengamos brevemente en aquellos temas fundamentales que están presentes en toda la obra y que conforman la idiosincrasia de la tragedia misma ${ }^{24}$.

Los ejes transversales que hemos escogido para caracterizar esta obra son el de la infelicidad, la fidelidad, la esclavitud, el disimulo, la madrastra y la furia. Antes de dar algunas pinceladas de todos ellos, deteniéndonos especialmente en los dos primeros, presentaremos un retrato somero de los principales personajes de esta tragedia.

\section{Personajes principales de la obra}

Ino aparece en escena como una esclava; su condición se debe, en un principio, al repudio que Atamante se ha visto obligado a darle debido a la propia conducta adúltera de Ino. Al final de la obra, sin embargo, limpio el honor de toda calumnia, esta recupera a su hijo, a su marido y el trono como reina de Tebas. De todos modos, el único móvil de Ino en toda la obra de teatro es el amor maternal hacia Safo y el peligro que intuye que su hijo corre en manos de una madrastra cruel y altiva como es Temisto.

\footnotetext{
${ }^{24}$ Es evidente que dada la brevedad de este artículo aquí sólo queremos señalar los puntos fundamentales de aquellos que pueden ser los temas capitales de la obra. Ni es exhaustiva la lista de los temas ni lo es el análisis que hacemos de cada uno de ellos.
} 
Temisto viene descrita como una esclava hecha reina, soberbia, iracunda, dominada por una pasión furibunda y dispuesta a derramar sangre inocente en cuanto se siente despechada por su marido y constata que a su hijo se le ha excluido de la sucesión monárquica. Su belleza es tal que Atamante no duda en llamarla «hechicera», puesto que su corazón ha caído preso del embrujo de una beldad sin igual. No obstante, la soberbia domina ese cuerpo tan hermoso de tal modo que no duda en quitarse la vida para evitar la mofa y la humillación de sus enemigos. Es más, en el punto de la muerte no duda en maldecir a Atamante para que sea infeliz perpetuamente.

Atamante es un personaje dominado por la culpa y por el remordimiento. Tal y como señala Ebersole, esta lucha interior entre su amor pasional y su deber regio y patrio lo convierte en «un personaje muy humano» ${ }^{25}$. Cegado por la belleza de Temisto, se dejó encadenar por esta pasión hasta llegar incluso a calumniar a su virtuosa esposa con tal de verse libre de cualquier obstáculo que le impidiera unirse carnalmente a Temisto. Lo suyo fue una pasión sexual en toda regla. Su crueldad llega, pues, a su cota más elevada con la expulsión de Ino, humillada y vilipendiada; Atamante se ha ganado con justicia el adjetivo de «perverso». Poco a poco, su espíritu atribulado lo tortura por tanto atropello cometido; a raíz de la muerte del calumniador en el campo de batalla, comienza en Atamante un verdadero proceso de conversión interior. Los consejos de Adrasto le darán la fuerza necesaria para corregir la injusticia cometida con su mujer Ino y con su hijo Safo. En cualquier caso, el Eólida es un hombre desdichado y desgraciado, bien sea porque, calumniando a su verdadera mujer Ino, la ha condenado al ostracismo y a una vida mísera - remordimiento que no le ha de dejar vivir tranquilo-, bien sea porque, al restituir a Safo a su lugar y al decidir devolver el trono a su esposa Ino, Atamante pierde un hijo, Nimias, y una mujer, Temisto, a los que, suo modo, también amaba.

Tanto Cadmo como Adrasto tienen un papel relevante en toda la obra, a pesar de que el primero sea un mero apunte genealógico en la tradición mítica de Atamante y que el segundo no exista en absoluto en el relato mítico que las literaturas griega y latina nos ofrecen de esta saga. El padre de Ino desempeña una función crucial en la obra teatral de Comella. En primer lugar, sirve de refugio a su despechada hija; en segundo lugar, entabla dura batalla con su yerno para restablecer la manchada honra de Ino's; no duda en oponerse al ambiguo comportamiento de Atamante con una libertad de espíritu y una valentía inusuales; tiene la audacia de raptar a su propio nieto y de querer huir de Tebas en la noche profunda; por último, él es el último responsable, junto a Creonte, del feliz trueque de los dos niños pequeños, motivo de júbilo para Ino y de desolación para Temisto. El Grande del Reino, Adrasto, es un personaje que se halla en la sombra,

${ }^{25}$ A. V. Ebersole, La obra teatral de Luciano Francisco Comella (1789-1806), Monografía, Albatros (Albatros hispanófila, 6), Valencia, 1985, pág. 57.

${ }^{26}$ Este hecho puede ser una influencia del teatro español del Siglo de Oro, en donde la temática de 'la limpieza del honor manchado' era capital en el desarrollo de tantas representaciones dramáticas: Peribáñez, El alcalde de Zalamea, El médico de su honra, etc. 
como fiel servidor de la hija de Cadmo y como leal vasallo del hijo de Eolo; sus palabras van haciendo mella tanto en el espíritu de Ino, como en el de Atamante o en el de Cadmo, y sus consejos serán cruciales en el desarrollo de la obra.

\section{La infelicidad}

En nuestra opinión, este tema es el concepto capital de toda la tragedia. Sólo la palabra «infeliz» aparece veintitrés veces en toda la representación, de las cuales en diez ocasiones se atribuye a Ino.

En efecto, esta noción es la que mejor define a la hija de Cadmo, que atribulada por la infame calumnia de su marido, debe someterse a la humillación de servir como esclava de su rival para poder abrazar a escondidas a su querido hijo Safo. El personaje que más veces repite la expresión «infeliz Ino» o «Ino infeliz» es Atamante (cuatro veces); él y Adrasto son los que más compasión tienen de ella a lo largo de la obra; también Cadmo caracteriza a su hija al final de la tragedia como desgraciada (IV 7; V 9) ${ }^{27}$. Atamante dejará de llamarla desdichada a partir del tercer acto y Adrasto sólo menciona en IV 4 qué duro es cambiar el destino «de una madre infeliz». De tal manera permea la infelicidad la figura de Ino que incluso su condición, simbolizada en las ropas de esclava que lleva («el trage infelíz», I 1) viene tildado con este adjetivo; y si la madre es desdichada, es normal que Adrasto refiera a Cadmo que Ino «de su infeliz llora el destino» (III 8) ${ }^{22}$.

Temisto, por otro lado, nunca llamará a Ino infeliz ${ }^{29}$, sino que sólo considera de esta suerte a su hijo (II 9; III 4; IV 13), que se ha de ver súbdito desgraciado del futuro rey de Tebas Safo. A Atamante le llamará «infeliz» en III 5 porque el Eólida no sabe el malévolo plan que ya ha concebido para dejar expedito el camino del trono a su hijo Nimias.

Atamante, aparte de las veces que usa este adjetivo en referencia a Ino, lo utiliza dos veces en la última escena de la obra, en primer lugar, para caracterizarse a sí mismo, ya que al intentar salvar a un hijo, ha perdido otro, y, en segundo lugar, para insultar el cadáver de Temisto («este aborto infeliz»).

\section{La fidelidad}

Es un tema capital en toda la obra. Sin tener en cuenta otros conceptos como «la fe» con el significado de 'fidelidad' o las voces «lealtad» y «leal», el binomio «fiel/infiel» aparece 19 veces. Lo más importante es ver quién apela a la fidelidad de quién y cómo responde ese personaje a esa llamada.

${ }_{27}$ A partir de ahora, el número del acto vendrá expresado en número romano y la escena en número arábigo.

${ }^{28}$ No obstante, Atamante limita la voz «infeliz» a Ino y para Safo utiliza la expresión «desventurada prole» (I 5 , dos veces).

${ }^{29}$ La propia Ino sólo utiliza dos veces este término para señalar la ínfima condición a la que se ve sometida (III 4; IV 12); en realidad, Ino apela a este carácter humilde y humillante para desobedecer a Temisto y no quitarse el velo que la dejaría al descubierto. 
El primer juego de fidelidad/infidelidad tiene lugar entre Ino-Temisto (esclava-reina). La hija de Hipseo no sólo se confía a su esclava, a la que no duda en llamar en repetidas ocasiones «amiga», sino que la denomina «fiel» en cuatro ocasiones (II 9 \{dos veces\}; III 4; V 5); en cambio, a Ino como reina sólo la puede denominar «una adúltera infiel» (III 5), en contraposición a su misma persona que considera fiel a Atamante (II 8; III 5). Temisto, una vez que se ha enterado de las intenciones de éste para con Safo, reprocha a su marido, «que infiel quebranta las leyes del amor» (IV 2). Ino, por su parte, finge fidelidad a su señora Temisto y, si bien ella no se opone directamente a los planes que traza la nueva esposa de Atamante, tampoco coopera (¿cómo podría hacerlo?) con ellos, ya que se niega a matar a quien, de hecho, es su propio hijo.

La hija de Cadmo utiliza la voz «fiel» para referirse exclusivamente a Adrastro (I 1 \{dos veces $\}$; III 3), quien le responde a su antigua reina con sus «lealtades» (I 1). En realidad, Adrasto es el siervo fiel que no se ha dejado vencer por las calumnias vertidas contra Ino y ha defendido su conducta honesta y virtuosa. Su fidelidad, sin embargo, no va en detrimento de la obediencia y la lealtad que guarda para con su rey y señor, Atamante, al que así denomina en dos ocasiones (I 4; III 8), si bien Idreno también será un fiel vasallo para Atamante a lo largo de la obra (I 5). Este personaje, por cierto, tacha al principio de la tragedia a Ino como «consorte infiel» (I 5), y siempre recela de la fidelidad de Adrasto respecto a su rey y señor.

Por último, Cadmo se remite a la fidelidad de Creonte (IV 7; $10 ; 11$ dos veces $\}$ ), en la que el capitán de la guardia nunca le defraudará (IV 7).

\section{La esclavitud}

Es un tema que ya ha sido tratado en el esquema que hemos presentado de los personajes.

La pregunta que Comella lanza al espectador / lector de su tragedia es: ¿quién es, en realidad, el verdadero esclavo en este drama? Ino aparece siempre como tal, pero ella posee un espíritu completamente libre por el amor que regala a su hijo. Atamante es un hombre encadenado a quien le cuesta muchísimo poderse liberar de los grilletes de Temisto que lo aprisionan. La hija de Hipseo es esclava de su soberbia y de su ira vengativa hasta el punto de matar y de quitarse a sí misma la vida. Por último, Cadmo, vencido y humillado en el campo de batalla, cargado de hierros, cepos y argollas, demuestra tener una mente lúcida y libre para no someterse al juego de Atamante y para tomar las determinaciones oportunas para bien de su hija y de su nieto.

\section{El disimulo}

Es un rasgo principal en toda la obra: el disimulo de uno para con otros.

En primer lugar, Ino se oculta de Temisto y de Atamante bajo el velo de la esclavitud y sólo el amor a su hijo revela al fiel servidor su verdadera identidad. Atamante oculta al mundo entero la calumnia que ha lanzado contra la 
virtuosa Ino y, sólo tres años después de la desgraciada maquinación, se atreve a revelar la fuente de su inquietud a Idreno. Es más, el Eólida ocultará a su actual esposa los planes de nombrar heredero al hijo de su rival y, hasta el último momento, el repudio que tiene intención de darle para que Ino pueda recuperar su puesto en palacio. Temisto también encubre a los demás personajes, excepto a Ino, sus perversas intenciones y aprovecha la noche y la oscuridad para clavar en el corazón de quien pensaba que era Safo el frío puñal de la muerte. Cadmo también camufla su huida de Tebas y, sobre todo, enmascara perfectamente el cambio de niño y de habitación al final de la obra.

\section{La madrastra}

En el mito de Atamante, el tema de la madrastra es fundamental en la versión I-F-H, si bien su presencia en los elementos más antiguos de esta leyenda ha sido cuestionada por varios autores, véase, por ejemplo, Krappe (1924, pág. 384) cuando asevera que el motivo de la madrastra sólo se ha incorporado a la narración primitiva en época más tardía ${ }^{30}$. Así, Friedländer ${ }^{31}$ cree que primero surge una mortal, probablemente sin identificar, que se mete entre medias de Atamante y la divina Néfele, poniendo en crisis el matrimonio; ésta figura adquirirá paulatinamente un halo maravilloso y se adecuará al prototipo de la madrastra cruel. Para la versión I-T hay que suponer que es la clave que explica todo el desarrollo de la acción, a saber, el plan de matar a los hijos de la anterior consorte de Atamante.

Sólo Temisto personificará el desgraciado rol de la cruel madrastra. Es este motivo, junto a la soberbia que la domina, el que la lleva a matar a Safo para que reine su hijo Nimias. Ino, que también era madrastra de Nimias (aunque sólo lato sensu, puesto que había sido repudiada), no guarda hacia el muchacho animadversión alguna.

\section{La furia}

Este concepto ha caracterizado durante mucho tiempo la figura de Atamante, que, enloquecido, mataba a su hijo Learco confundiéndole con un animal en una montería. En la obra de Comella, por el contrario, este furor o $\mu \alpha v i ́ \alpha$ entendido como castigo divino que produce la enajenación mental para que se mate a un ser querido no se produce.

La furia que el dramaturgo español nos presenta es, en primer lugar, el furor bellicus de Cadmo que, desencajado por la rabia de un padre deshonrado, intenta vencer a toda costa en el campo de batalla; en segundo lugar, el furor criminis de Atamante, que lo oprime y lo tortura por el delito cometido contra

\footnotetext{
30 Véase, por ejemplo, Krappe, «La légende d'Athamas et de Phrixos», REG, 37, 1924, pág. 384, cuando asevera que el motivo de la madrastra sólo se ha incorporado a la narración primitiva en época más tardía.

31 Friedländer, «Hele», en Paulys Realencyclopädie der classischen Altertumswissenschaft (RE), coord. por P. Wissowa, 1913, col. 161.
} 
su virtuosa esposa Ino; también le posee al Eólida el furor eroticus, que lo encadena a la pasión de la hermosa Temisto; en último lugar, el furor ultrix de Temisto, que, por todos los medios intenta hacer todo el mal que puede a Atamante y a Ino.

En cualquier caso, jamás aparece la locura como fruto de un castigo divino y en ningún momento se pierde la razón o la consciencia de lo que se está haciendo.

\section{Conclusiones}

La obra de Francisco Comella es un extraordinario ejemplo de recepción del mito de Atamante en los escenarios españoles del s. XVIII. Estamos de acuerdo con Ebersole cuando afirma que «Comella ha construido un argumento cuyas tensiones dramáticas mantienen el interés hasta el desenlace» ${ }^{32}$. Si bien el dramaturgo español se aparta en algunos puntos principales de lo que nosotros hemos denominado versión I-T, a saber, la intervención de Cadmo y su papel determinante en toda la obra, la acusación calumniosa de adulterio por parte de Atamante respecto a su esposa Ino, la presencia de ésta como esclava motu proprio, el ardid por el que el hijo de Ino (y no los hijos) se salva en detrimento del vástago (uno sólo) de Temisto, hay que reconocer que Comella ha conservado el esquema general de esta versión.

En efecto, Ino es caracterizada como una figura positiva que sufre por su hijo (o sus hijos, según Higino) y que tiene suficiente osadía como para ir al palacio de su enemiga para mostrarle su cariño ${ }^{33}$. Temisto, altiva y orgullosa, no duda en actuar como madrastra contra la descendencia de Ino para favorecer a la suya propia y en suicidarse si su plan fracasa estrepitosamente. El nudo principal de esta versión se mantiene inalterado: Temisto mata a su descendencia con su propia mano cuando, de hecho, lo que quería era matar a la descendencia de Ino y, al darse cuenta de su error, se suicida.

Por último, llama la atención el papel de Atamante, que tanto en Higino como en Nonno de Panópolis es prácticamente nulo (por esta razón lo hemos denominado homo ignauus) y, sin embargo, para Comella interviene decisivamente, no sólo con el acta de repudio de Ino, sino, sobre todo, con el nombramiento de Safo como heredero del trono de Tebas, hecho que desencadenará la furia de Temisto. Ésta, y no Atamante, es presa de una ira vengativa que bien podría remitirse a la famosa $\mu \alpha v i ́ \alpha$ o al renombrado furor de Atamante en la versión I-L-M con las diferencias señaladas en el texto.

32 A. V. Ebersole, op. cit., 1985, pág. 56.

${ }^{33} \mathrm{La}$ Ino de Higino es más resuelta y tiene más iniciativa que la Ino de Comella, que es bastante pusilánime y timorata. 